difficult to see how the new theory can be directly relevant to the study of Earih-satellite orbits, and more explanation would certainly have been welcome.

It cannot be pretended that the book is easy to read, though this is due partly to the difficulty of the theory. When the author has the chance to relax from the rigours of mathematics, as in the introductory paragraphs of each chapter, his writing is lucid and lively : the last paragraph on page 87 is particularly admirable in giving new life to a well-worn metaphor. The book is printed by a photographic method from a typescript. The resulting product is extremely clear, but the appearance of some of the formulæ would have been improved by more frequent use of small type, especially in fractions. Trivial errors and misprints are commendably rare, though equation (1-39) of Chapter 2 seems to be wholly erroneous and should be replaced by equation (2-3) of Chapter 3 .

D. G. KING-Heue

\section{FROM NUCLEUS TO UNIVERSE}

From Nucleus to Universe

A Course of Selected Lectures in Physics and Astronomy, University of Sydney, January 11-22, 1960. Edited by Prof. S. T. Butler and Prof. H. Messel. Pp. 335. (Sydney : Shakespeare Head Press, Pty., Ltd., 1960.) $84 s$.

HE excellent lectures delivered at the first of the summer schools for science teachers at the University of Sydney, sponsored by the Nuclear Research Foundation, were reviewed in these columns some two years ago (Nature, 182, $623 ; 1958$ ) and have recently been re-issued by Messrs. Macmillan. This present volume contains those given at the third summer school of January 1960. They are of the same high standard, and given by a most distinguished group of scientists. The chief difference from the earlier volume is the thread of continuity that makes it more like a symposium on a single central theme.

The first contribution, by Prof. S. T. Butler, on introductory atomic and nuclear physics, deals with nuclear structure in general, and the interaction between charged particles and radiation. Next, Prof. C. N. Watson-Munro, on advances in thermonuclear research, discusses the physical conditions for maintaining a thermonuclear reaction and the orders of magnitude to be expected. The problems of stability in both linear and toroidal pinch machines, the field convolutions of the Stellerator type, the magneticbottle devices and the means of ion injection, are described with helpful diagrams; and there is a short summary of the means available for studying what goes on inside a plasma.

Prof. G. Gamow's account of the universe and its origin is the longest individual contribution. $\mathrm{He}$ discusses both the evolutionary and steady-state cosmologies, together with the kind of evidence which would help to discriminate between them. On the evolutionary theory, for the first tenth of the lifetime of the universe, radiation must have preponderated over matter; and the first critical stage from which the protogalaxies emerged came when matter began to play a significant part in affairs. This lively field of controversy was, it appears, submitted to American astronomers by the Gallup pollsters ; unanimity was expressed in the answer to one quostion only-that asking whether such a poll was of any use! Prof. Bart J. Bok continues Prof. Gamow's story with an account of the observational basis for stellar evolution.

R. Q. Twiss, on stellar interferometers, describes the Michelson interferometer as originally used for the measurement of stellar diameters, and then shows how, as an 'intensity' interferometer, it was adapted to measurements on radio stars. The next stage in the development, which involved so much discussion a few years ago on the correlation of photons in two coherent interfering beams, was to bring it back as an intensity interferometer into optics. This work has led to a new type of interferometer, of which an account is given.

T. Gold discusses the origin of the solar system, the structure and evolution of the Earth, and the probable state of the surface of the Moon. A. A. Day, on the interior of the Earth, takes two models of the mantlecore arrangement and describes the physieal conditions associated with each, mentioning the information expected to be given by the project of boring a hole down to the Mohorovičić-discontinuity. "Space Physics" is the title of D. F. Martyn's contribution, which describes the problems of launching satellites, the processes of observing and tracking and obtaining information from them, and the results of satellite observations. H. D. Rathgeber describes the Van Allen belt of radiation, and its probable part in the origin of the auroræ. G. B. A. MeCusker gives an account of cosmic radiation, mentioning the association with solar flares, and describing some of the very high-energy nuclear events observed in photographic emulsions exposed to cosmic rays. The study of conditions in the upper atmosphere by observations of meteor trails, micrometeorites and the zodiacal light are among the topics mentioned by G. Elford in his account of the science of meteors. Finally, K. B. Mather writes of research in Antarctica during the International Geophysical Year, and of work on the structure of the Antarctic continent.

The original aim of the summer school was to give teachers the means of arousing enthusiasm for science among their pupils, and to stimulate the flow of entrants to the university science courses ; and the 1958 publication was effectively a permanent record for the participants. This is a more luxurious production, which is intended for a wider circle of teachers, and could be understood by their more enterprising pupils or by the interested layman. I do not feel justified in complaining about the price, which seems fair for a handsome limited edition of real intrinsic value; indeed, it would be conniving at the major education heresy of our times to imply that one can expect to get what is first-rate on the cheap. At the same time, it is a pity that this book is out of the reach of the thousands of teachers who would read it with delight, and of most of the librarians who are working to a budget. There must be some way of meeting the latent demand and the not-so-latent need for such a book; and perhaps on a future occasion it may be found. For this is more than a shot in the arm for the jaded teacher whose equipment is a little obsolete; it embodies the new outlook, or the resurgence, of a science that is still an adventure of the human spirit rather than the mere handmaid of technology. If we are to begin to think seriously, as we shall surely have to, about science as a liberal study in schools, this is the kind of book that will direct our thoughts along the right lines.

G. R. NOAKES 